\title{
THE REINFORCEMENT OF SAND BY FIBRES WITH A NON-UNIFORM SHAPE
}

\author{
Pavel KOUDELA ${ }^{1}$, Juraj CHALMOVSKÝ ${ }^{1}$, Lumír MIČA*1
}

\begin{abstract}
The reinforcement of soil is used to improve its strength and stiffness. The standard method of soil reinforcement is an application of geosynthetics. Soil reinforcement by distributed discrete fibres represents an alternative to those techniques. Currently used fibres have a straight shape, uniform cross-section, and smooth surface, which is not optimal in terms of the fibre-soil interaction. In this study, fibres with a variable shape were utilized. The fibres were fabricated using a fused deposition modelling technology. Firstly, a brief theoretical background is presented. Then, the proposed shapes of the fibres and their manufacturing process are described. The mechanical properties of the soil-fibre composite were investigated through consolidated drained triaxial tests. Well-graded coarse sand and poorly-graded fine sand were used. A higher peak shear strength was observed in the case of fibres with a variable shape. The effect of the variable shape of the fibres on the peak shear strength was higher in the case of the coarse sand.
\end{abstract}

\section{Address}

1 Institute of Geotechnics, Faculty of Civil Engineering, Brno University of Technology, Brno, Czech Republic

* Corresponding author: koudela.p@fce.vutbr.cz

\section{Key words}

- Fibre reinforcement,

- Fusion deposition modelling,

- Shear strength,

- Sand,

- Soil.

\section{INTRODUCTION}

Improving soil properties by fibre reinforcement to reach a higher bearing capacity has been used in geotechnical engineering for quite a few years. This concept was first described in terms of soil and reinforcement interaction by Vidal (1969). Steel and plastic strips were used in this study. The effect of adding man-made fibres is to some extent analogous to the natural effect of tree roots. The effect of tree roots on slope stability was studied by Waldron (1977).

Many authors have analyzed the behaviour of soil-fibre composites solely on an experimental basis by introducing so-called improvement factors, which quantify the degree of improvement of certain properties (e.g., shear strength and ductility). Noorzad and Zarinkolaei (2015) conducted a series of 40 triaxial and 40 direct shear tests with polypropylene fibres in fine sand. The fibre lengths, concentrations, and confining stresses were varied throughout the test campaign. The improvement ratio increased by increasing the fibre contents and lengths. Higher values were reached in the case of triaxial tests. Adding fibres also reduces the brittleness index and thus improves the ductility.

An extensive study of fibre-reinforced sand was performed by Ranjan et al. (1996). It included polypropylene and two kinds of natural fibres. Moreover, five types of sand were used. The study resulted in a set of about 500 triaxial tests performed to determine the effect of various parameters of fibre-reinforced soil. A mathematical model quantifying the shear strength of the fibre-soil composite was proposed. It was based on a regression analysis of the tests performed. Another approach to quantify the shear strength of fibre-reinforced soils was proposed by Zornberg (2002), who suggested a bilinear failure envelope. The first part of the failure criterion is governed by the pull-out of fibres from soil. As the confining stress increases, the tensile breakage of the fibres becomes a failure mode. Michalowski and Zhao (1996) and Michalowski and Čermák (2003) applied an energy-based homogenization technique to derive the macroscopic 
failure criterion of a composite with randomly-oriented fibres. The proposed yield condition again consisted of linear and non-linear segments associated with the slip and yielding of fibres, respectively.

Combinations of fibre reinforcements with more common admixtures such as lime (Wei et al., 2018), fly ash (Chen et al., 2015), and cement (Olgun, 2013) have also been recently studied. It is well known that adding these binding agents can reduce the ductility of soils. The simultaneous addition of a binding agent and fibres could reverse this process.

A common feature of all the above-mentioned works is that they utilize straight fibres with a uniform shape and mostly with a smooth surface (Figure 4). These features, which mainly occur due to the production process of the fibres, are not optimal in terms of fibre-soil interactions. Several improvements can be observed in fibre-reinforced concrete (FRC). To increase their pullout capacity, steel-crimped fibres and fibres terminated with hooks and plates are being used.

The concept of soil reinforcement utilizing fibres with a variable shape is presented in this study. Fibres are made by fusion deposition modelling (3D printing). Rapid progress in this area already allows for the large-scale, highly-accurate production of components with complex geometries. The basic properties of the soil-fibre composites are summarised in the following section. Then, the proposed shapes of the fibres are introduced, and the manufacturing process is specified. The testing program, which consists of a series of consolidated drained tests on the compacted samples, is presented in the next section.

\section{PROPERTIES OF MATERIALS AND PROCEDURES USED IN THE STUDY}

\subsection{Fibre-soil composite}

Soil in its general state is a three-phase system (the solid, liquid and gas phases). The solid phase is represented by soil grains, while the liquid and gas phases form the content of voids. If fibres are added to the soil, they form the second component of the solid phase. A block diagram of fibre-reinforced soil together with a designation of the relevant quantities is shown in Fig. 1.
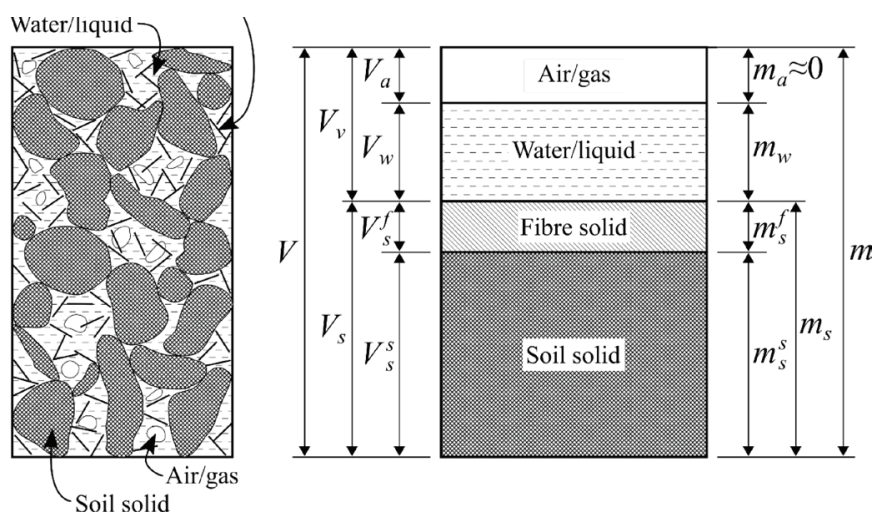

Fig. 1 Phase diagram of a fibre-reinforced soil composite (according to Shukla, 2017)

The void ratio of the reinforced soil $(e)$ is given by Eq. 1, where is the volume of voids, and, are the volumes of the soil and fibre solids, respectively.

$$
e_{r}=\frac{V_{v}}{V_{s}}=\frac{V_{v}}{V_{S}^{s}+V_{s}^{f}}
$$

The fibre concentration is quantified via the volumetric fibre content according to Eq. 2.

$$
p_{v, f}=\frac{V_{s}^{f}}{V_{s}^{s}}
$$

The shape of commonly used fibres with a circular cross-section is characterized via the aspect ratio (Eq. 3), where and are the length and radius, respectively. In the case of fibres with variable shapes, the length of the fibre is replaced by the length of its centreline.

$$
\eta=\frac{l}{2 r}
$$

\subsection{Soil}

Well-graded coarse sand (SW) and poorly-graded fine sand (SP) with different types of fibres were used in this study. Their grain size distributions and basic properties are stated in Fig. 2 and Tab. 1, respectively.

Tab. 1 Properties of soils adopted in this study

\begin{tabular}{ccccccc}
\hline $\begin{array}{c}\text { Soil } \\
\text { type }\end{array}$ & $\begin{array}{c}\mathrm{d}_{10} \\
{[\mathrm{~mm}]}\end{array}$ & $\begin{array}{c}\mathrm{d}_{30} \\
{[\mathrm{~mm}]}\end{array}$ & $\begin{array}{c}\mathrm{d}_{60} \\
{[\mathrm{~mm}]}\end{array}$ & $\mathrm{C}_{\mathrm{c}}[-]$ & $\mathrm{C}_{\mathrm{u}}[-]$ & Gs [-] \\
\hline SP & 0.204 & 0.322 & 0.577 & 0.88 & 2.83 & 2.548 \\
SW & 0.073 & 0.467 & 1.153 & 2.58 & 15.69 & 2.757 \\
\hline
\end{tabular}

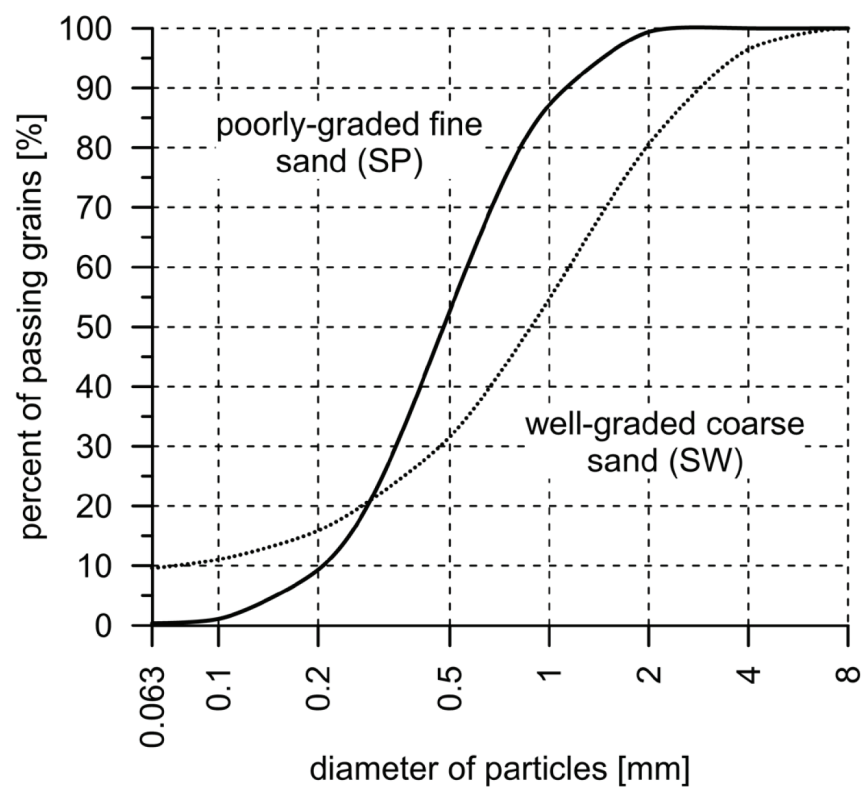

Fig. 2 Grain size distribution of coarse and fine sand

\subsection{Design and fibre manufacturing}

Three shapes of fibres were analysed in this study. A straight fibre was considered as the reference type. The drawings and isometric views of all the shapes are shown in Fig. 5. The dimensions of the fibres were chosen according to Wei et al. (2018), who recommended the maximum length of fibres to be between $30 \%$ and $40 \%$ of the sample diameter. The reference straightforward fibre is $20 \mathrm{~mm}$ long. The length of the fibres with a variable shape was chosen to maintain the same volume 
$\left(9.60 \mathrm{~mm}^{3}\right)$ of the all types of fibres. Thus, the same number of fibres is used in each sample. The aspect ratio of the fibres is 25.6.

The fibres were fabricated with a commonly available 3D printer that uses the technology of fused deposition modelling (FDM), also known as fused filament fabrication (FFF). The three-dimensional objects made by FDM technology are created layer by layer with melted plastic being extruded from a nozzle (Fig. 3). The nozzle is moving at a few tenths of a millimetre above a heated platform in a prescribing pattern. After the layer is completed, the platform moves down in a one-layer thickness, and the process continues in this cycle until the object is completed. The objects for 3D printing can be prepared in computer-aided design (CAD) applications for 3D modelling. The output of the CAD applications is a stereolithography (STL) file format, which is further processed by a "slicer" application. The slicer slices the STL object into layers and prepares the instruction set for the $3 \mathrm{D}$ printer.

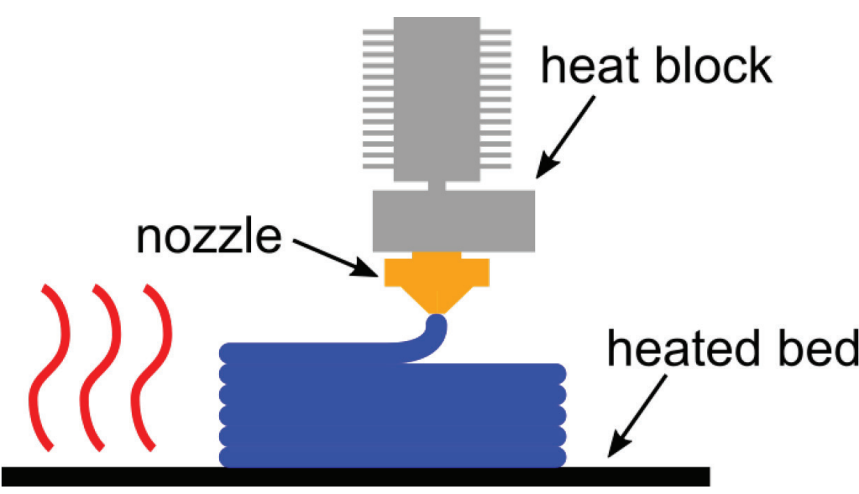

Fig. 3 Illustration of the printing process

The most common material of the fibres used in fibre-reinforced concrete and fibre-reinforced soil (FRS) is made from polypropylene (PP) and polyethylene (PE) (Fig. 4). Unfortunately, PE is not available for $3 \mathrm{D}$ printing on the market. Instead, materials such as polylactic acid (PLA), polyethylene terephthalate (PET), acrylonitrile butadiene styrene (ABS), polycarbonate (PC), polyamide (PA), etc., are used for 3D printing. PP, the most common material for fibres, has a few disadvantages such as low adhesion to the printing bed. It is a semi-crystalline material with a precise melting point, which requires a precise temperature control. ABS behaves similarly. In particular, the shrinkage during the cooling of a printed object occurs when ABS is used. The main disadvantage of PC and PA is the absorption of the moisture from the air, thereby resulting in subsequent printing problems. PLA is the most favourable material for 3D printing from a technological point of view, but it is stiff and brittle.

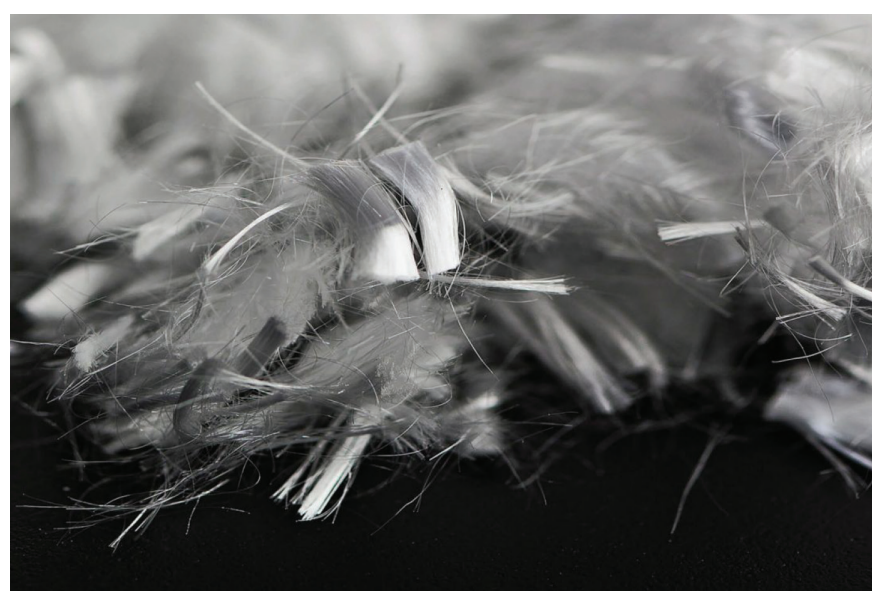

Fig. 4 Commonly used fibres in fibre-reinforced concrete

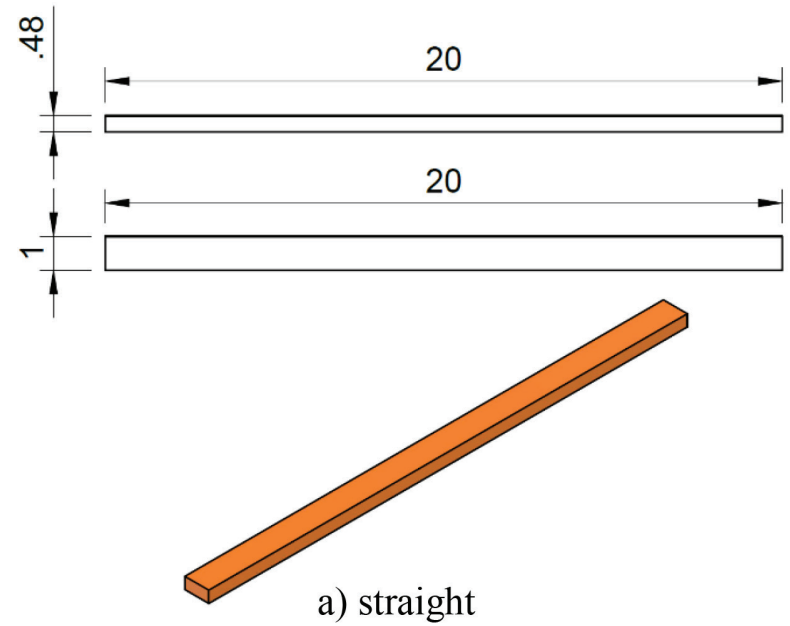

a) straight

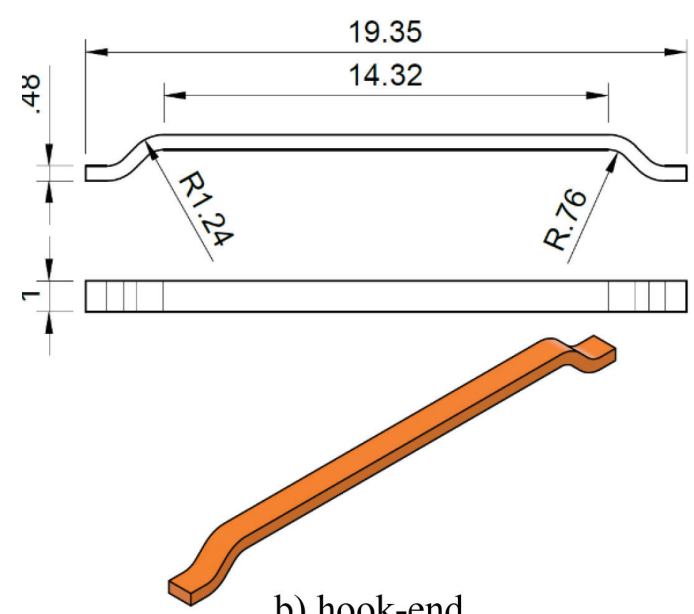

b) hook-end

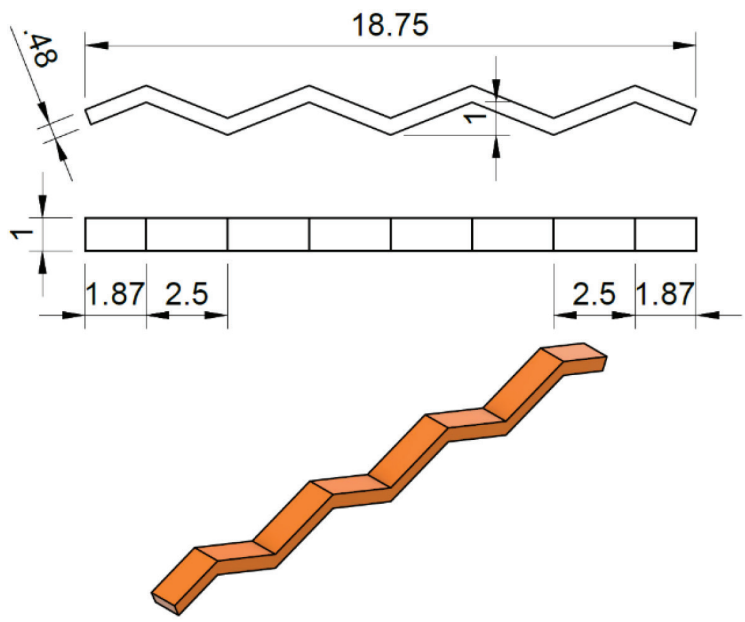

c) profiled

Fig. 5 Drawings and isometric views of the fibres manufactured by $3 D$ printing

PET for 3D printing, which is modified by adding a glycol (PET-G), was chosen for manufacturing the fibres in this study. Good adhesion to the printing bed and good printability are the advantages of this material. The elasticity of the PET-G eliminates breakage of the fibres during preparation of the sample by compaction. The density of the base material (filament) for the production of the fibres was $1.23 \mathrm{~g} / \mathrm{cm}^{3}$ 


\section{LABORATORY TESTING}

A series of drained triaxial tests (CD) on the compacted samples was performed. The tested samples were $50 \mathrm{~mm}$ in diameter and 100 $\mathrm{mm}$ in height. A volumetric fibre content was used. To achieve a better homogeneity of the samples, the compaction process was divided into 5 stages (layers). Each layer contained the same number of fibres given by the chosen. A fibre-soil composite was prepared and thoroughly mixed separately for each layer. The material was then placed into a mould and carefully compacted (Fig. 6).

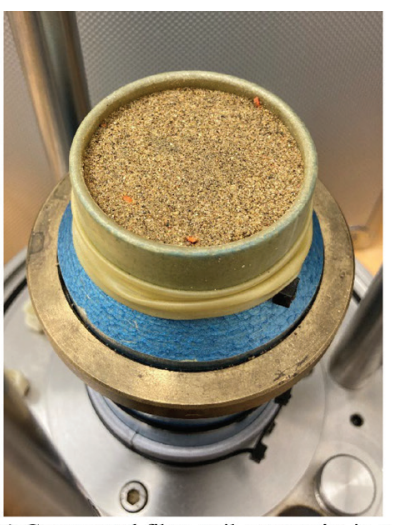

a) Compacted fibre-soil composite in a monld

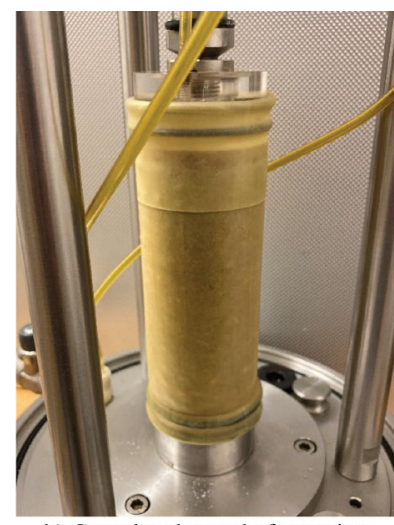

b) Completed sample for testing
Fig. 6 Preparation of the triaxial sample

Each triaxial test consisted of three stages. The saturation stage was initiated by water percolation to minimize the amount of air entrapped in the voids. The sample was slowly filled with de-aired water $(1 \mathrm{ml} /$ $\mathrm{min}$ ), while the confining pressure of $30 \mathrm{kPa}$ was maintained. The percolation was terminated after a steady-state flow throughout the sample was reached. Subsequently, the backpressure was slowly increased at a rate of $0.5 \mathrm{kPa} / \mathrm{min}$ to dissolve the residual air bubbles. The effective stress of $30 \mathrm{kPa}$ was maintained. The samples were then consolidated to the effective mean stress. The loading of the samples was driven as a constant strain rate procedure with a constant cell pressure. The strain rate was determined according to ČSN EN ISO 17892-9, which was obtained from the consolidation phase. The value obtained was further reduced to a value of $0.025 \mathrm{~mm} / \mathrm{min}$ to ensure a uniform distribution of the pore pressure in the sample during the shearing.

Tab. 2 Summary of the test the results for the coarse sand (SW)
The quantification of the improvement due to the inclusion of the fibres was performed according to Skukla (2017). The two factors below were evaluated:

- The deviator stress improvement factor at failure $I_{d f}$ (Eq. 4), where $\left(\sigma_{1}-\sigma_{3}\right)_{p U}$ is the deviatoric peak stress of the unreinforced soil; is the deviatoric peak stress of the reinforced soil.

$$
I_{d f}=\frac{\Delta\left(\sigma_{1}-\sigma_{3}\right)}{\left(\sigma_{1}-\sigma_{3}\right)_{p U}}=\frac{\left(\sigma_{1}-\sigma_{3}\right)_{p R}-\left(\sigma_{1}-\sigma_{3}\right)_{p U}}{\left(\sigma_{1}-\sigma_{3}\right)_{p U}}=\frac{\left(\sigma_{1}-\sigma_{3}\right)_{p R}}{\left(\sigma_{1}-\sigma_{3}\right)_{p U}}-1
$$

- Second, the deviator stress ratio at failure $\operatorname{DSR}_{f}$ (Eq. 5):

$$
D S R_{f}=\frac{\left(\sigma_{1}-\sigma_{3}\right)_{p R}}{\left(\sigma_{1}-\sigma_{3}\right)_{p U}}
$$

\section{RESULTS AND DISCUSSION}

The improvement factors $\left(I_{d \rho} D S R_{\rho}\right)$, the peak angle of the internal friction $\left(\varphi_{\text {peak }}\right)$ and the angle of the internal friction at a strain level of $30 \%\left(\varphi_{30 \%}\right)$ are summarised in Tab. 2 (coarse sand - SW) and Tab. 3 (fine sand - SP). The test of the coarse sand sample with straight fibres was terminated due to a premature puncture of a membrane; therefore, the $\varphi_{30 \%}$ is not given. The deviatoric stress - axial strain plots are shown in Fig. 7 and 8. Finally, the peak angles of the internal friction are compared in Fig. 9.

The addition of straight fibres led to a significant increase in the peak shear strength for both types of sand. The degree of improvement of the samples with straight fibres was higher for the coarse sand $\left(I_{d f}=0.63\right)$ compared to the fine sand sample $\left(I_{d f}=0.30\right)$. The modification of the shape of the fibres resulted in a further increase in the peak shear strength in the case of the coarse sand samples $\left(I_{d f}=0.89\right.$ - profiled fibre; $I_{d f}=1.52$ - hook-end fibre). However, the effect of the fibre shape was significantly lower for the fine sand samples (Tab. 3). The improvement factor for the profiled fibre $\left(I_{d f}=0.16\right)$ was even lower than for the straight one $\left(I_{d f}=0.30\right)$. The authors assume that this might be due to the difficult compaction of the poorly-graded fine sand in the vicinity of the profiled fibres, which may have local-ly increased the void ratio in the zones around the fibres. Thus, the effect of the variable fibre shape is closely related to the grain size distribution and compaction of the soils. It is also interesting to note that the post-peak shear stress gradually converges towards the shear strength of the unreinforced samples. This might be due to the gradual rotation of the individual fibres to a position parallel to the shear zone. The orientation of the fibres was analysed by (Gray, 1983), who concluded that fibres oriented parallel to

\begin{tabular}{|c|c|c|c|c|c|c|}
\hline Reinforcement & $p_{v, f}^{*}[\%]$ & $\left(\sigma_{1}-\sigma_{3}\right)_{p}[\mathrm{kPa}]$ & $I_{d f}[-]$ & $D S R_{f}[-]$ & $\varphi_{\text {peak }}\left[{ }^{\circ}\right]$ & $\varphi_{\text {ult,30\% }}\left[{ }^{\circ}\right]$ \\
\hline- & 0 & 576 & - & - & 41.1 & 33.88 \\
\hline straight & 4 & 940 & 0.632 & 1.632 & 49.3 & - \\
\hline profiled & 4 & 1090 & 0.892 & 1.892 & 51.6 & 36.42 \\
\hline hook-end & 4 & 1451 & 1.519 & 2.519 & 56.0 & 42.8 \\
\hline
\end{tabular}

Tab. 3 Summary of the test results for the fine sand (SP)

\begin{tabular}{|c|c|c|c|c|c|c|}
\hline Reinforcement & $p_{v_{f}}^{*}[\%]$ & $\left(\sigma_{1}-\sigma_{3}\right)_{p}[\mathrm{kPa}]$ & $I_{d f}[-]$ & $D S R_{f}[-]$ & $\varphi_{\text {peak }}\left[{ }^{\circ}\right]$ & $\varphi_{\text {ult,30\% }}\left[^{\circ}\right]$ \\
\hline- & 0 & 694 & - & - & 44.2 & 33.2 \\
\hline straight & 4 & 903 & 0.301 & 1.301 & 48.6 & 35.7 \\
\hline profiled & 4 & 808 & 0.164 & 1.164 & 46.8 & 36.9 \\
\hline hook-end & 4 & 1007 & 0.451 & 1.451 & 50.0 & 36.1 \\
\hline
\end{tabular}




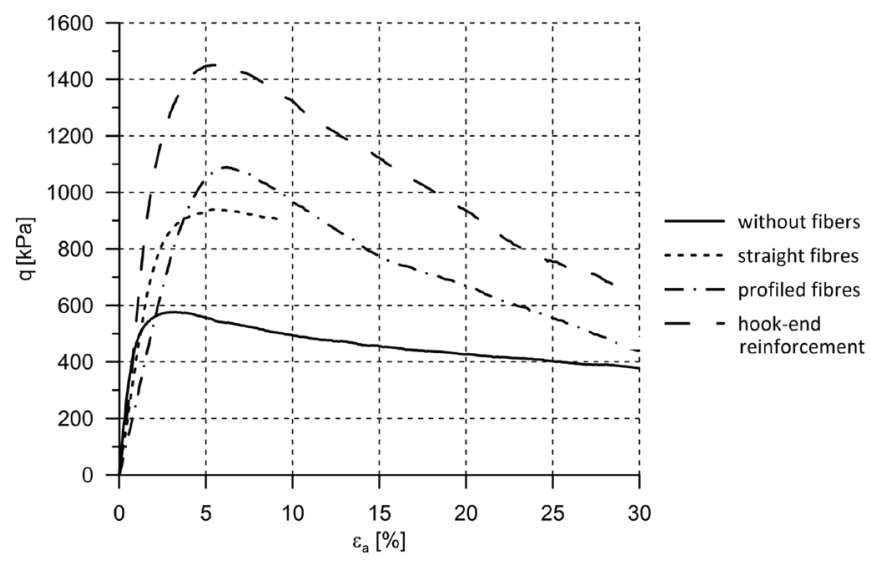

Fig 7 Stress-strain plots, coarse sand (SW)

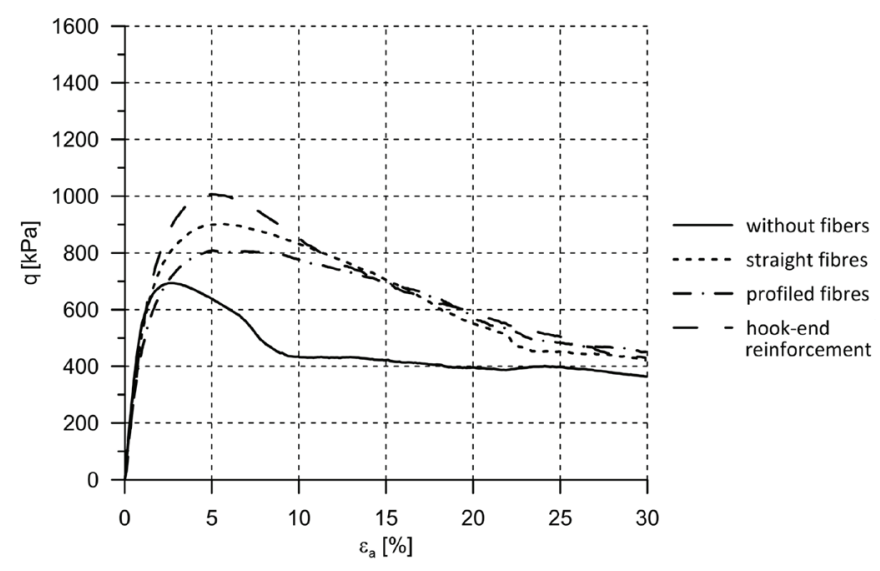

Fig. 8 Stress-strain plots, fine sand (SP)

a shear zone contributed least to the overall strength. The soil-fibre composite exhibited lower initial stiffness compared to the unreinforced samples. The reasons might be as follows: a) the lower stiffness of the fibres compared to the soil grains; b) difficulties in the soil compaction around the profiled fibres.

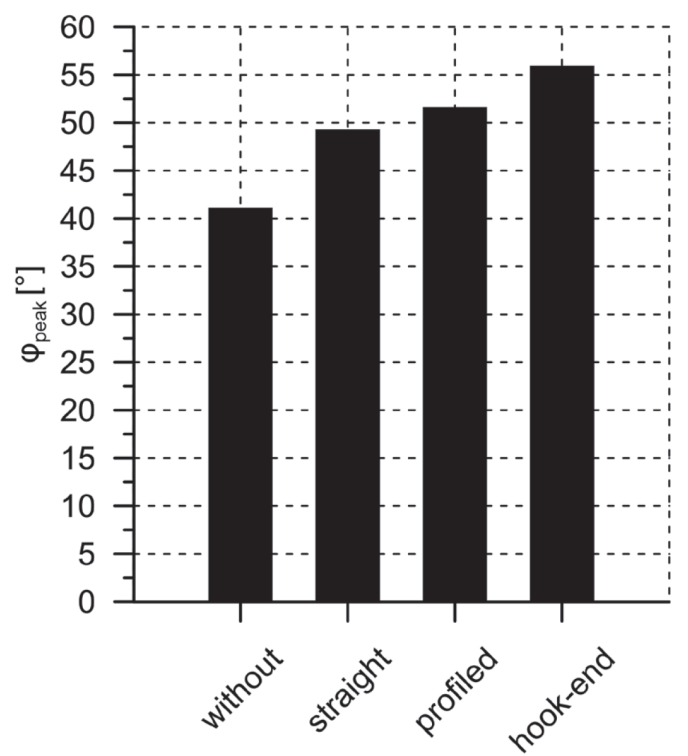

a) coarse sand (well-graded)

\section{CONCLUSION}

A novel application of fibres with a non-uniform shape for soil reinforcement was presented in this study. The fibres were manufactured utilizing the fused deposition modelling technology (also known as 3D printing). The mechanical properties of the soil-fibre composite were tested on two soil types: poorly-graded fine sand and well-graded coarse sand. A series of consolidated drained triaxial tests were performed.

The addition of straight fibres led to an increase in the peak angle on the internal friction by $8.2^{\circ}$ (the well-graded coarse sand sample) and $4.4^{\circ}$ (the poorly-graded fine sample). Thus, the degree of improvement of the fine sand is approximately half compared to that of the coarse sand. Similarly, the variable shape of the fibres had a much greater effect in the case of the well-graded coarse samples. The highest degree of improvement was achieved using hook-end fibres regardless of the soil type: the increase in the peak angle of the internal friction was $15^{\circ}$ for the well-graded sand and $5.8^{\circ}$ for the poorly-graded sand. Therefore, the grain-size distribution was an important factor significantly affecting the efficiency of the fibre reinforcement. The reinforced samples exhibited a post-peak softening that gradually converged towards the unreinforced stress-strain curves. This might be due to the gradual rotation of the fibres. Despite their variable shapes, the fibres analysed in this study are still 1D elements, and the response of the soil-fibre composite significantly depends on their orientation. A study of 2D and 3D elements that have the same shape in two and three directions, respectively, is currently underway.

\section{Acknowledgement}

This paper was supported by the Ministry of Education, Youth and Sports in Research Grant No. FAST-S-19-5724.

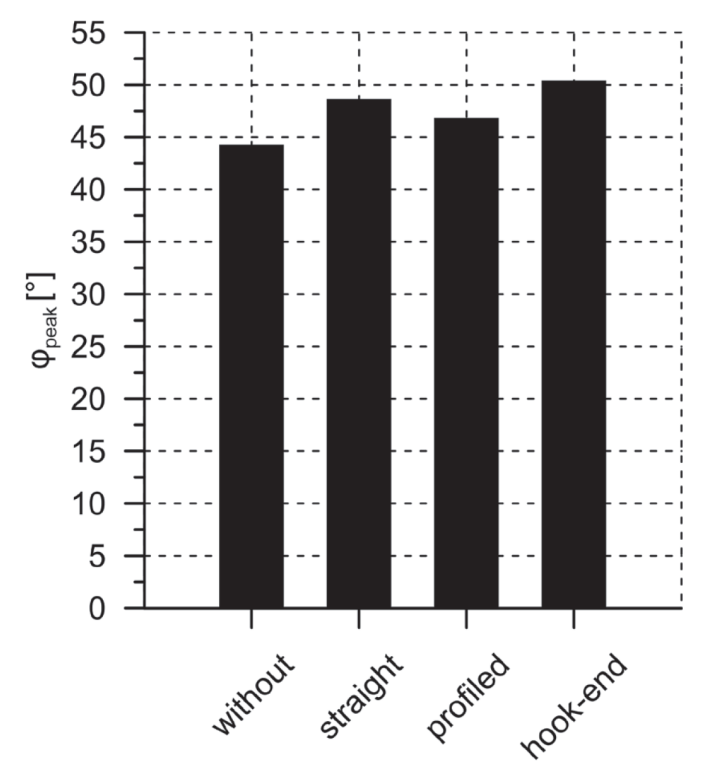

b) fine sand (poorly graded)

Fig. 9 Observed angles of internal friction at the peak state 


\section{REFERENCES}

Chen, M. - Shen, S. L. - Arulrajah A. - Wu, H. N. - Hou D. - Xu Y. (2015) Laboratory evaluation on the effectiveness of polypropylene fibers on the strength of fiber-reinforced and cement-stabilized Shanghai soft clay. Geotextiles and Geomembranes, 43(6), pp. 515-523.

Gray, D.H. - Ohashi, H. (1983) Mechanics of Fiber Reinforcement in Sand. Journal of Geotechnical Engineering, 109(3), pp. 335353.

Michalowski, R.L. - Čermák, J. (2003) Triaxial Compression of Sand Reinforced with Fibers. Journal of Geotechnical and Geoenvironmental Engineering, 129(2), pp. 125-136.

Michalowski, R.L. - Zhao, A. (1996) Failure of Fiber-Reinforced Granular Soils. Journal of Geotechnical Engineering, 122(3), pp. 226-234.

Noorzad, R. - Zarinkolaei, S.T.G. (2015) Comparison of Mechanical Properties of Fiber-Reinforced Sand under Triaxial Compression and Direct Shear. Open Geosciences, 7(1), pp. 547-558.

Olgun, M. (2013) Effects of polypropylene fiber inclusion on the strength and volume change characteristics of cement-fly ash stabilized clay soil. Geosynthetics International, 20(4), pp. 263-275.
Ranjan, G. - Vasan, R.M. - Charan, H.D. (1996) Probabilistic Analysis of Randomly Distributed Fiber-Reinforced Soil. Journal of Geotechnical Engineering, 122(6), pp. 419-426.

Shukla, S.K. (2017) Fundamentals of Fibre-Reinforced Soil Engineering, Singapore: Springer Singapore.

Vidal, H. (1969) The Principle of Reinforced Earth. Highway Research Record, (282), pp. 1-16.

Waldron, L.J. (1977) The Shear Resistance of Root-Permeated Homogeneous and Stratified Soil. Soil Science Society of America Journal, 41(5), pp. 843-849.

Wei, L. - Chai S. X. - Zhang H. Y. - Shi Q. (2018) Mechanical properties of soil reinforced with both lime and four kinds of fiber. Construction and Building Materials, 172, pp. 300-308.

Zornberg, J.G. (2002) Discrete framework for limit equilibrium analysis of fibre-reinforced soil. Géotechnique, 52(8), pp. 593-604. 